\title{
Developmental change of the biorbital angle in normal Japanese infants
}

This article was published in the following Dove Press journal:

Clinical Ophthalmology

\author{
Teiji Yagasaki ${ }^{1,2}$ \\ Yoshimi Yokoyama ${ }^{2}$ \\ Makiko Tsukui ${ }^{2}$ \\ 'Yagasaki Eye Clinic, Ichinomiya, Aichi, \\ Japan; ${ }^{2}$ Department of Ophthalmology, \\ Japan Community Health Care \\ Organization Chukyo Hospital, \\ Nagoya, Aichi, Japan
}

Purpose: To investigate postnatal changes in the biorbital angle in normal Japanese children. Subjects and methods: Axial imaging of the orbit in the transverse plane of the horizontal extraocular muscles was obtained in 129 ophthalmologically healthy infants (age ranging from a few months to 11 years). The opening angle between both lateral walls of the orbit was defined as the biorbital angle.

Results: The mean biorbital angle in 11 infants less than a year of age was $105.0^{\circ} \pm 6.0^{\circ}$. The mean biorbital angles for each of the subsequent age groups were $97.7^{\circ} \pm 3.1^{\circ}, 96.2^{\circ} \pm 4.0^{\circ}$, $96.3^{\circ} \pm 4.1^{\circ}, 92.8^{\circ} \pm 3.8^{\circ}, 92.3^{\circ} \pm 2.3^{\circ}, 93.1^{\circ} \pm 2.8^{\circ}, 91.5^{\circ} \pm 3.9^{\circ}, 91.9^{\circ} \pm 2.3^{\circ}, 91.4^{\circ} \pm 2.3^{\circ}$, and $90.9^{\circ} \pm 3.1^{\circ}$. The mean biorbital angle in infants less than a year old was significantly larger than those found in the groups of infants older than 1 year $(P<0.01$, Newman-Keuls test).

Conclusion: The biorbital angle in infants less than a year old was larger than that found in infants older than 1 year, with this larger biorbital angle potentially the causative factor of the observed exotropia seen in $70 \%-80 \%$ of newborns gradually disappearing in most cases by $2-4$ months of age.

Keywords: orbit, computed tomography, magnetic resonance imaging, exotropia, infant

\section{Introduction}

It is well-known that there is continuous development of the orbit after birth, ${ }^{1}$ with several reports documenting changes in the volume of the orbit and the diameter of the orbital opening in both newborns and infants..$^{2-7}$ Although previous studies have clearly shown that the angle of the orbit gradually changes from wider to narrower as the gestation progresses, ${ }^{8-10}$ there have been few studies that examined the development of the opening angle of the orbit after birth. ${ }^{11-13}$ Tsukitome et al reported changes in the opening angle of the optic nerve and the angle of the ocular orbit with increasing age in normal Japanese children. Although there was no change with age in the opening angle of the optic nerve, defined as the angle formed by the intersection of a line running through the left optic nerve and a vertical line passing through the center of the nose, they found a relatively rapid decrease in the opening angle of the orbit, defined as the angle formed by the intersection of a line running tangentially along the deep lateral wall of the left orbit and a vertical line passing through the center of the nose, within 2-3 years of age, after which the angle then stabilized. Furthermore, this decrease in the opening angle of the orbit with increasing age was statistically significant. ${ }^{13}$ These findings additionally suggest that the decrease in the opening angle of the orbit may contribute to the decrease in the exodeviation that is seen in $70 \%-80 \%$ of normal newborns. ${ }^{14}$ Furthermore, this morphological change might provide important information on the management of strabismus in infants. 
This study investigated the relationship between changes in the biorbital angle, which was defined as the opening angle between both lateral walls of the orbit, ${ }^{11}$ and increasing age in normal Japanese children.

\section{Subjects and methods}

A total of 129 ophthalmologically healthy infants (age ranging from a few months to 11 years: mean age $\pm \mathrm{SD}=5.14 \pm 2.65$ years) who were scheduled to undergo head axial computed tomography (CT) or MRI to diagnose the origin of their headaches or to rule out intracranial injuries or diseases were randomly selected for enrollment in this study. Children with conditions potentially affecting the normal formation of their skull or facial bones, such as hydrocephalus or craniosynostosis, were excluded. All subjects were divided into subgroups according to their age. The number and age of subjects in each group were as follows: Group 0, 11 subjects $<1$ year old; Group 1, 11 subjects 1 to $<2$ years old; Group 2, 11 subjects 2 to $<3$ years old; Group 3, 10 subjects 3 to $<4$ years old; Group 4, 9 subjects 4 to $<5$ years old; Group 5, 17 subjects 5 to $<6$ years old; Group 6, 11 subjects 6 to $<7$ years old; Group 7, 13 subjects 7 to $<8$ years old; Group 8, 12 subjects 8 to $<9$ years old; Group 9, 14 subjects to $<10$ years old; and Group 10, 10 subjects 10 to $<11$ years old.

Axial CT or MRI of the orbit in the transverse plane of the horizontal extraocular muscles was performed in order to measure the opening angle of the orbit, with the biorbital angle defined as the angle formed between the two lines running along the deep lateral wall of both orbits (Figure 1). The CT system used in this study was the Aquilion Prime Focus Edition (Toshiba, Tokyo, Japan). Imaging conditions

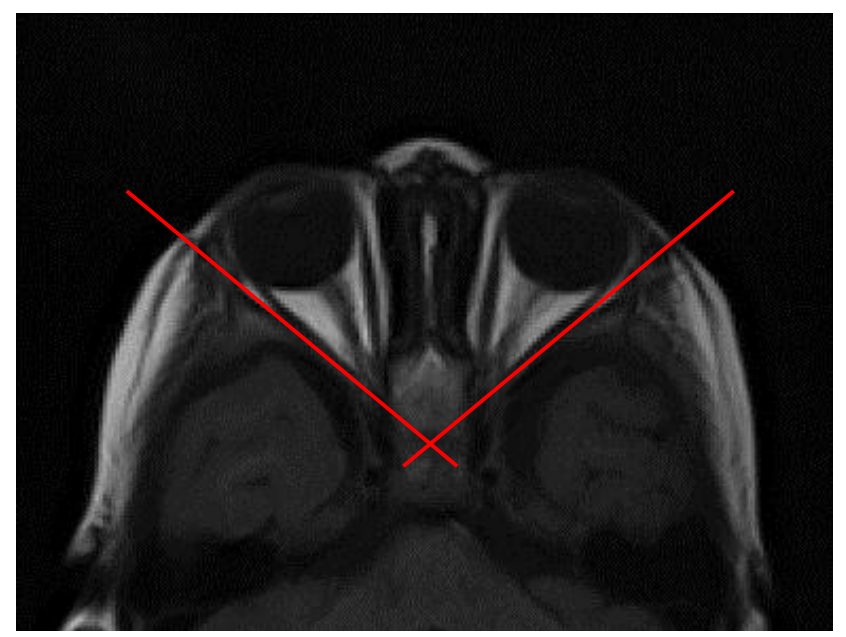

Figure I Axial MRI image of the biorbital angle for a representative typical infant. Note: The biorbital angle was defined as the angle formed by two lines running tangentially along the deep lateral wall of the orbit. used during the evaluations included tube voltage, $120 \mathrm{kV}$; tube current, $170 \mathrm{~mA}$; slice thickness, $0.5 \mathrm{~mm}$; 80 data acquisition system; and helical scan pitch, 0.637 . The measurement of the slice thickness for each image was $1 \mathrm{~mm}$. The MRI system used for the evaluations in this study was the Intera 1.5T (Philips Medical Systems Nederland B.V., Eindhoven, the Netherlands). The acquisition parameters of the high-resolution, T1-weighted MRI were as follows: FoV, $200 \mathrm{~mm}$; flip angle, $80^{\circ}$; repetition time, $577 \mathrm{msec}$; echo time, $12 \mathrm{msec}$; slice thickness, $5 \mathrm{~mm}$; and slice gap, $1 \mathrm{~mm}$. Younger children who did not cooperate during the MRI scanning were anesthetized or sedated using triclofos sodium (Tricloryl, GlaxoSmithKline Pharmaceuticals, Brentford, UK).

To ensure the accuracy of the biorbital angle, all measurements were performed by two independent observers, who were blinded to the age of the subject. Each observer repeated the measurements for each image three times, and the mean value was as a representative value. For the statistical analyses, the mean values of the two observers were used.

After entering the collected data into a Microsoft Excel worksheet (Microsoft Inc., Redmond, WA, USA), those data were analyzed for statistical significance with proper advices of a biostatistician. Due to the unequal sample sizes for each group, the mean values of each group were compared using the Newman-Keuls test, with $P<0.05$ considered significant. The $95 \%$ CI was calculated for all data.

This study was conducted in accordance with the tenets of the Declaration of Helsinki, and written informed consents were taken from all subjects or their parents who participated in this study, with ethical approval for the study obtained from the Clinical Research Ethics Committee of the Japan Community Health Care Organization Chukyo Hospital (approval no. 2017044).

\section{Results}

The mean biorbital angle for Group 0 was $105.0^{\circ} \pm 6.0^{\circ}$. The mean biorbital angles for Group 1 through Group 10 were $97.7^{\circ} \pm 3.1^{\circ}, 96.2^{\circ} \pm 4.0^{\circ}, 96.3^{\circ} \pm 4.1^{\circ}, 92.8^{\circ} \pm 3.8^{\circ}$, $92.3^{\circ} \pm 2.3^{\circ}, 93.1^{\circ} \pm 2.8^{\circ}, 91.5^{\circ} \pm 3.9^{\circ}, 91.9^{\circ} \pm 2.3^{\circ}, 91.4^{\circ} \pm 2.3^{\circ}$, and $90.9^{\circ} \pm 3.1^{\circ}$, respectively (Table 1). Although there were no statistical differences found for the biorbital angle between any two of the groups, with the exception of Group 0 , the mean biorbital angle in infants less than a year old was significantly larger than those found in all the groups of infants older than 1 year $(P<0.01$, Newman-Keuls test). The trend line analysis carried out and the logarithmic fit showed the statistically significant correlation $(y=-2.9 \ln (x)+96.418$, $r=0.283, P<0.001)$. Figure 2 presents the range drawn from the $95 \%$ CI that was calculated from all the data. 
Table I The biorbital angle in each age

\begin{tabular}{|c|c|c|c|c|}
\hline Groups & $\mathbf{N}$ & Mean & SD & $\begin{array}{l}\text { Newman- } \\
\text { Keuls test }\end{array}$ \\
\hline Group $0(<I Y)$ & II & 105.0 & 6.0 & \\
\hline Group I $(I Y \leq,<2 Y)$ & II & 97.7 & 3.1 & $P<0.01$ \\
\hline Group $2(2 Y \leq,<3 Y)$ & II & 96.2 & 4.0 & $P<0.00$ I \\
\hline Group $3(3 Y \leq,<4 Y)$ & 10 & 96.3 & 4.1 & $P<0.001$ \\
\hline Group $4(4 Y \leq,<5 Y)$ & 9 & 92.8 & 3.8 & $P<0.00$ I \\
\hline Group $5(5 Y \leq,<6 Y)$ & 17 & 92.3 & 2.3 & $P<0.001$ \\
\hline Group $6(6 Y \leq,<7 Y)$ & II & 93.1 & 2.8 & $P<0.00$ I \\
\hline Group $7(7 Y \leq,<8 Y)$ & 13 & 91.5 & 3.9 & $P<0.001$ \\
\hline Group 8 (8Y $\leq,<9 Y)$ & 12 & 91.9 & 3.1 & $P<0.001$ \\
\hline Group 9 (9Y $\leq,<10 Y)$ & 14 & 91.4 & 2.3 & $P<0.001$ \\
\hline Group $10(10 Y \leq,<I I Y)$ & 10 & 90.9 & 3.1 & $P<0.001$ \\
\hline
\end{tabular}

Notes: Axial MRI image of the biorbital angle for a representative typical infant. The biorbital angle was defined as the angle formed by two lines running tangentially along the deep lateral wall of the orbit.

Abbreviations: N, number; $\mathrm{Y}$, year(s) old.

\section{Discussion}

de Haan et al specifically described the detailed changes in the shape of the eyeball and in the position of the orbit. The angle between both optic nerves was $180^{\circ}$ during embryonic stage $16,84^{\circ}$ at stage 23 , which then further narrowed to $55^{\circ}$ in a fetus with a crown-breech length of $65 \mathrm{~mm}$ at term. These authors also showed that the angle between the two lines through the anatomical eye sockets, which was measured from the center of the pupil to the center of the optic nerve disc, exhibited narrowing from the initial $180^{\circ}$ that was observed at stage $16^{\circ}$ to $30^{\circ}$ in adults. ${ }^{9}$ Although the authors did not provide any further information on the morphological changes seen in the biorbital angle, it can be speculated that the biorbital angle became narrower, with the eye position changing from exotropic to orthotropic.
It is well-known that both the volume of the orbital growth and the shape continue to change after birth, with the normal lateral orbital walls exhibiting an approximate $90^{\circ}$ angle in relation to other adolescents and adults. ${ }^{10,11}$ However, there have only been a few studies that have investigated developmental changes of the biorbital angle after birth. It has been reported that the angle of the orbit measured between the medial and lateral orbital wall decreased until the age of 1 year, with little change noted thereafter. ${ }^{11-13}$ The biorbital angle used in our study was approximately equal to the total amount of the right and left angles measured by Escaravage and Dutton. ${ }^{12}$ Furthermore, our results showed that the biorbital angle became narrower at the age of 1 year and then remained unchanged, which matches with the previous results of Escaravage and Dutton. ${ }^{12}$

Tsukitome et al defined the opening angle of the orbit as the angle formed by the intersection of the line running tangentially along the deep lateral wall of the left orbit and the vertical line passing through the center of the nose. ${ }^{13}$ In addition, they also reported that there was a relatively rapid decrease in the opening angle of the orbit within 2-3 years after birth, after which the angle then stabilized. This decrease in the opening angle of the orbit with increasing age was statistically significant. Furthermore, the logarithmic curve generated by the regression analysis that best fitted the relationship between the two parameters during this developmental period was (y (angle of ocular orbit, degrees) $=48.7-3.7$ $\log \times$ age (years): $\left.r^{2}=0.188, P<0.001\right) .{ }^{13}$ The biorbital angle in our study was defined as the total area for the right and left opening of the angle of the orbit, which is the same as that defined by Tsukitome et al. ${ }^{13}$ Our study also showed the

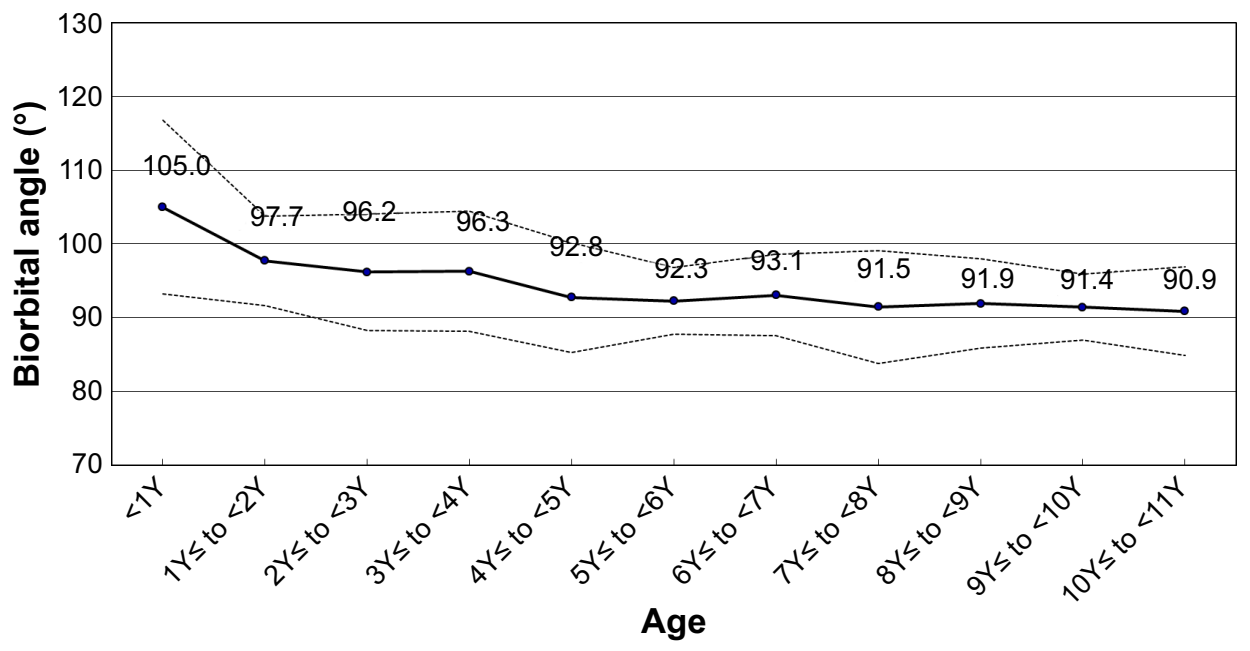

Figure 2 The range drawn from the $95 \% \mathrm{Cl}$ calculated from all data.

Notes: Numbers are the mean of the biorbital angle in each age. The solid line is a line connecting each mean angle and two dotted lines are lines connecting each upper and each lower $95 \% \mathrm{Cl}$ value. 
statistically significant correlation $(P<0.001)$ by the logarithmic fit $(y=-2.9 \ln (x)+96.418, r=0.283)$. Therefore, the postnatal decrease observed in the angle between the lateral walls of both orbits in our current study was the same as that reported in the study by Tsukitome et al. However, the question that needs to be answered is what does this change in the biorbital angle actually reflect?

Although there has yet to be any no direct evidence on the relationship between the abnormal biorbital angle and the strabismus, a few reports have suggested that this relationship might indeed exist. Strabismus complication rates in craniosynostosis have been reported to range from $39 \%$ to $90.9 \%$, with the most common type of strabismus in Crouzon and Apert syndromes reported to be exotropia. ${ }^{15,16}$ Morax reported that the eye position in Crouzon syndrome after sagittal expansion surgery of the orbit changed from preoperative exotropia to postoperative orthophoria in eight of nine patients. ${ }^{17}$

The same ocular alignment change from exotropic to esotropic has also been reported after craniofacial surgery for Apert syndrome. ${ }^{18,19}$ Sagittal expansion surgery of the orbit, such as fronto-orbital advancement, Le Fort III advancement, or monobloc advancement, can produce meaningful decreases in the opening angle of the orbits between both lateral walls. Thus, the biorbital angle used in our study along with the previously reported large biorbital angle may be one of the causative factors of exotropia. In 1989, Archer et al reported that approximately $70 \%$ of newborns showed constant or intermittent exotropia, with this exotropic deviation gradually disappearing in most cases by $2-4$ months of age. ${ }^{14}$ However, while it is not clear as to why this change in the ocular alignment has yet to be definitively investigated after the original report by Archer et al, our current findings may help to elucidate the reason for this postnatal ocular position change. Furthermore, diagnostic imaging of the orbit may help to further clarify the causative factor in abnormal ocular alignment in some forms of strabismus.

\section{Limitations}

There were some limitations for our current study. First, the results of our analysis were based on single-center data, and thus, the sample size for our current study was not all that large. However, because our results are similar to those reported by previous studies, ${ }^{11-13}$ our findings appear to be strong enough to prove the presence of developmental changes in the biorbital angle of normal Japanese infants. Another limitation of our study was that even though all the subjects evaluated were examined by either the CT or MRI systems, the axial imaging of the orbit and the two images obtained by two systems in the same subject were not compared. However, because there were no differences in the anatomical details between the two images obtained by the CT or MRI systems, especially for the boney tissue, ${ }^{20}$ choosing either the CT or MRI system would appear to be reasonable for measuring the orbital angle. In spite of the overall limitations, our study revealed that the postnatal change of the biorbital angle that occurs in normal infants rapidly stabilizes to the approximately normal $90^{\circ}$ angle that is observed in adults.

\section{Conclusion}

The biorbital angle in infants less than a year old was larger than that found in children older than 1 year. This finding suggests that larger biorbital angle may be one of the causative factors of exodeviation in normal newborns and may provide important information on the diagnosis and management of special forms of strabismus in infants.

\section{Acknowledgments}

The authors would like to thank Dr Mariko Maeda for her useful discussions and advices. The abstract of this paper was presented at the 44th annual meeting of the American Association for Pediatric Ophthalmology and Strabismus held at Washington DC/USA; March 18-22; as a poster with interim findings. The abstract was published in e Journal of the American Association for Pediatric Ophthalmology and Strabismus in August 2018;22(4):e84.

\section{Author contributions}

All authors contributed toward data analysis, drafting and revising the paper and agree to be accountable for all aspects of the work.

\section{Disclosure}

The authors report no conflicts of interest in this work.

\section{References}

1. Duke-Elder S, Cook C. The post-natal period. System of ophthalmology, normal and abnormal development, part 1. In: Duke-Elder S, editor. Embryology. Vol. III. London: Henry Kimpton; 1963:304-313.

2. Furuta M. Measurement of orbital volume by computed tomography: especially on the growth of the orbit. Jpn J Ophthalmol. 2001;45(6): 600-606.

3. Bentley RP, Sgouros S, Natarajan K, Dover MS, Hockley AD. Normal changes in orbital volume during childhood. J Neurosurg. 2002;96(4): 742-746.

4. Yang G, Wang J, Chang Q, et al. Digital evaluation of orbital development in Chinese children with congenital microphthalmia. Am J Ophthalmol. 2012;154(3):601-609.

5. Farkas LG, Posnick JC, Hreczko TM, Pron GE. Growth patterns in the orbital region: a morphometric study. Cleft Palate Craniofac J. 1992; 29(4):315-318.

6. Chau A, Fung K, Yip L, Yap M. Orbital development in Hong Kong Chinese subjects. Ophthalmic Physiol Opt. 2004;24(5):436-439. 
7. Elkhamary SM, Sallam AA, Kahtani EA, et al. Measurement of bony orbital volume with computed tomography (CT) in healthy eyes of Saudi children. J Cancer Prev Curr Res. 2016;6(4):00215.

8. Zimmermann AA, Armstrong EL, Scammon RE. The change in position of the eyeballs during fetal life. Anat Rec. 1934;59(1):109-134.

9. de Haan AB, Willekens B, Klooster J, et al. The prenatal development of the human orbit. Strabismus. 2006;14(1):51-56.

10. Becker MH, McCarthy JG. Congenital abnormalities. In: Gonzalez CF, Becker MH, Flanagan JC, editors. Diagnostic Imaging in Ophthalmology. New York: Springer-Verlag; 1986:115-187.

11. Lemke BN, Lucarelli MJ. Anatomy of the ocular adnexa, orbit, and related facial structures. In: Black EH, Nesi FA, Gladstone GJ, editors. Smith and Nesi's Ophthalmic Plastic and Reconstructive Surgery. New York: Springer-Verlag; 2012:3-58.

12. Escaravage GK, Dutton JJ. Age-related changes in the pediatric human orbit on CT. Ophthalmic Plast Reconstr Surg. 2013;29(3):150-156.

13. Tsukitome H, Hatsukawa Y, Morimitsu T, Yagasaki T, Kondo M. Changes in angle of optic nerve and angle of ocular orbit with increasing age in Japanese children. Br J Ophthalmol. 2015;99(2):263-266.
14. Archer SM, Sondhi N, Helveston EM. Strabismus in infancy. Ophthalmology. 1989;96(1):133-137.

15. Rosenberg JB, Tepper OM, Medow NB. Strabismus in craniosynostosis. J Pediatr Ophthalmol Strabismus. 2013;50(3):140-148.

16. Kreiborg S, Cohen MM. Ocular manifestations of Apert and Crouzon syndromes: qualitative and quantitative findings. J Craniofac Surg. 2010; 21(5):1354-1357.

17. Morax S. Change in eye position after cranio-facial surgery. J Maxillofac Surg. 1984;12(2):47-55.

18. Khong JJ, Anderson P, Gray TL, Hammerton M, Selva D, David D Ophthalmic findings in Apert syndrome prior to craniofacial surgery. Am J Ophthalmol. 2006;142(2):328-330.

19. Khong JJ, Anderson P, Gray TL, et al. Ophthalmic findings in Apert's syndrome after craniofacial surgery: twenty-nine years' experience. Ophthalmology. 2006;113(2):347-352.

20. Nayak B, Desai S, Maheshwari S. Interpretation of magnetic resonance imaging of orbit: simplified for ophthalmologists (Part I). J Clin Ophthalmol Res. 2013;1(1):29-35.
Clinical Ophthalmology

\section{Publish your work in this journal}

Clinical Ophthalmology is an international, peer-reviewed journal covering all subspecialties within ophthalmology. Key topics include: Optometry; Visual science; Pharmacology and drug therapy in eye diseases; Basic Sciences; Primary and Secondary eye care; Patient Safety and Quality of Care Improvements. This journal is indexed on

Submit your manuscript here: http://www.dovepress.com/clinical-ophthalmology-journal

\section{Dovepress}

PubMed Central and CAS, and is the official journal of The Society of Clinical Ophthalmology (SCO). The manuscript management system is completely online and includes a very quick and fair peer-review system, which is all easy to use. Visit http://www.dovepress.com/ testimonials.php to read real quotes from published authors. 